\title{
Family Disaster Planning Untuk Meningkatkan Pengetahuan dan Sikap Disabilitas Dalam Menghadapi Bencana
}

\author{
Brigitta Ayu Dwi Susanti ${ }^{1^{*}}$, Eva Nurlina Aprilia ${ }^{2}$ \\ ${ }^{1,2}$ Fakultas Ilmu Kesehatan, STIKES Notokusumo Yogyakarta \\ *Email: brigittaayudwisusanti@gmail.com
}

\begin{abstract}
Background: The family as the smallest unit in society has a share in disaster preparedness, especially for families with disabilities, this is due to the lack of disaster management for families with disabilities. According to a 2013 UN global survey, worldwide 20\% of people with disabilities can save themselves and $31 \%$ of people say they need someone who can help during a disaster. Imogiri Bantul District is the red zone that suffered the worst damage and from the results of preliminary studies disaster prepared families have not been formed in real terms. Aims of this study is to analize effect pamily disaster planning to improve knowledge and ability disability person in disaster. Methods: Quasi eksperiment pre and post test without control. Research instrument with preparedness instrument. There are 31 subjects in this research. Results: Knowledge and attitude to prepare disaster in disabilities can improve significantly $p<0.005$ (Wilcoxon test). Conclusion: With family disaster planning the knowledge and attitude can improve significantly to prepare disaster in disabilities and their family.
\end{abstract}

Keywords: disability, family disaster planning, preparedness

\section{PENDAHULUAN}

Bencana yang terjadi dapat menimbulkan kerugian moral maupun materil jika tidak ada kesiapsiagaan dampak akan semakin banyak (Bakornas Penanggulangan bencana, 2007). Kesiapsiagaan bencana merupakan kegiatan untuk meminimalkan risiko bencana dimana kesiapsiagaan dimiliki oleh siapapun di mana berada melingkupi menanggapi kejadian bencana dengan cepat dan tepat guna. Yogyakarta merupakan tempat yang sering terjadi bencana terutama bencana gempa bumi. Letak geografis Yogyakarta yang berada di persimpangan lempeng dunia sehingga memungkinkan terjadinya gempa bumi. Data dari persebaran episentrum gempa yang terjadi pada tahun 1900-2000an tercatat dengan skala magnitude 5 (Dwisiwi et al., 2012). Gempa yang terjadi di Yogyakarta pada 27 Mei 2006 menimbulkan korban yang tidak sedikit jumlahnya 5716 orang tewas dan 37927 mengalami luka-luka sehingga kewaspadaan terhadap bencana sangatlah penting (BNPB, 2018). Dampak bencana perlu perhatian khusus karena tidak dapat diprediksi (Nurudin, 2015). Indonesia mengalami dampak yang merugikan akibat bencana dalam kurung waktu 10 tahun, untuk proses rehabilitasi pasca bencana, hal tersebut disebabkan karena peran satuan terkecil masyarakat yaitu keluarga dalam mitigasi bencana masih belum dilibatkan secara penuh (Bapennas, 2014).

Manajemen bencana salah satunya dengan proses kesiapsiagaan sehingga dibutuhkan kerjasama dari berbagai pihak (Firmansyah, Rasni dan Rondhianto, 2014). Kegiatan yang dapat dilakukan untuk meminimalkan dampak bencana adalah dengan penyuluhan kesehatan, peran media , dan pola perilaku masyarakat (Ikbal dan Sari, 2018). Perawat mempunyai peran diberbagai fase kebencanaan mulai dari persiapan, sebagai advikat, dan pemberi layanan kesehatan (Azizah, Ratnawati dan Setyoadi, 2015). Penanggulangan bencana berbasis keluarga merupakan suatu hal penting 
terdiri dari serangkaian aktivitas pada saat pra, emergency dan pasca bencana untuk mengurangi jumlah korban. Keluarga sebagai unit terkecil di dalam masyarakat mempunyai pengaruh yang besar terhadap pemberian informasi dan sosialisasi untuk penanggulangan risiko bencana yang terjadi (Yuwanto, 2019). Tidak hanya keluarga pada umumnya namun keluarga dengan disabilitas juga harus diperhatikan karena masih minimnya manajemen bencana bagi keluarga dengan disabilitas (Wardhana, 2015).

Menurut survey global PBB tahun 2013, diseluruh dunia hanya 20\% penyandang disabilitas bisa menyelamatkan diri, dan $31 \%$ penyandang mengatakan bahwa mereka butuh seseorang yang mampu membantu ketika bencana. Oleh karena itu pentingnya family disaster planning di keluarga disabilitas. Penyandang disabilitas mengalami tingkat kematian yang lebih tinggi dan lebih besar daripada populasi umum. Penelitian menunjukkan bahwa penyandang disabilitas yang terkena dampak bencana mengalami peningkatan risiko yang lebih tinggi karena pengetahuan dan kesiapsiagaan keluarga yang membantu penyandang disabilitas masih rendah pada saat terjadi bencana (Wolf-Fordham et al., 2015). Kurangnya pengetahuan dalam menangani penyandang disabilitas dalam situasi bencana menyebabkan masalah yang jauh lebih besar. Banyak dari mereka hidup dengan peningkatan risiko dan keterpaparan bencana, mereka sangat rentan terhadap risiko dan lebih mungkin meninggal atau terluka saat bencana daripada orang normal pada umumnya (UNISDR, 2014).

Kecamatan Imogiri Bantul menurut peta kerusakan gempa tahun 2006 merupakan zona merah yang mengalami kerusakan terparah dan keluarga siaga bencana dari hasil studi pendahuluan belum terbentuk secara riil. Jumlah keluarga disabilitas tahun 2019 sebanyak 15 KK. Aktivitas kesiapsiagaan bencana dalam keluarga disabilitas masih belum dilakukan, belum adanya kegiatan yang melibatkan multistruktural dalam membentuk keluarga siaga bencana. Pembentukan family disaster planning (keluarga tanggap bencana) diharapkan mampu mempersiapkan kesiapsiagaan keluarga dalam menghadapi bencana. Tujuan dari penelitian ini untuk mengatahui efek family disaster planning dalam meningkatkan pengetahuan dan sikap disabilitas dalam menghadapi bencana.

\section{METODE PENELITIAN}

Jenis penelitian kuantitatif dengan quasi eksperimen pre post test without control grup. Kuesioner yang digunakan dari Lenawida, 2011. Kuesioner yang digunakan yaitu kesiapsiagaan bencana Uji validitas Pearson Product Moment $r=0.647$ dan uji realibilitas dengan Cronbach Coefficient Alpha dengan hasil 0.959. Penelitian dilaksanakan di Kecamatan Imogiri Bantul Yogyakarta pada bulan Juni 2020. Variabel yang digunakan adalah pengetahuan, sikap, dukungan anggota keluarga. Dalam penelitian ini menggunakan metode family disaster planning. Family disaster planning merupakan kegiatan yang ditujukan untuk disabilitas maupun keluarganya dalam mempersiapkan jika terjadi bencana. Family disaster planning dalam penelitian ini bekerjasama dengan tagana dan secara door to door diberikan materi, poster,video, dan praktik secara langsung jika terjadi bencana. Untuk 
melihat pengaruh family disaster terhadap pengetahuan dan sikap menggunakan uji wilxocon.

\section{HASIL PENELITIAN}

Subyek penelitian terdiri dari 31 penelitian terdiri dari umur responden, pekerjaan dan pendidikan. Penelitian yang dilakukan pada Juni 2020 dapat di deskripsikan karakteristik responden seperti tabel berikut ini :

KK. Karakteristik responden dalam

Tabel 1. Karakteristik Responden KK Berdasarkan Usia di Wukirsari,Bantul $(n=31)$

\begin{tabular}{lcc}
\hline Karakteristik & Fruekuensi (F) & Presentasi \\
\hline $21-30$ tahun & 4 & 12,9 \\
$31-40$ tahun & 2 & 6,5 \\
$41-50$ tahun & 9 & 29,0 \\
$51-60$ tahun & 10 & 32,3 \\
$>60$ tahun & 6 & 19,4 \\
\hline Total & $\mathbf{3 1}$ & $\mathbf{1 0 0 , 0}$ \\
\hline
\end{tabular}

Sumber: Data Primer

Tabel 2. Karakteristik Responden KK Berdasarkan Pekerjaan di Kelurahan Wukirsari, Imogiri, Bantul Juni 2020 ( $\mathrm{n}=31)$

\begin{tabular}{lcc}
\hline Karakteristik & Fruekuensi (F) & Presentasi \\
\hline Guru & 1 & 3,2 \\
Wiraswasta & 2 & 6,5 \\
Pedagang & 3 & 9,7 \\
Pengrajin & 6 & 19,4 \\
Buruh & 7 & 22,6 \\
Petani & 2 & 6,5 \\
Lain-Lain & 10 & 32,3 \\
\hline Total & $\mathbf{3 1}$ & $\mathbf{1 0 0 . 0}$ \\
\hline
\end{tabular}

Sumber : Data primer

Tabel 3. Karakteristik Responden KK Berdasarkan Pendidikan di Kelurahan Wukirsari, Imogiri, Bantul Juni $2020(\mathrm{n}=31)$

\begin{tabular}{lcc}
\hline Karakteristik & Fruekuensi (F) & Presentasi \\
\hline Tidak sekolah & 8 & 25,8 \\
Sekolah Dasar (SD) & 11 & 35,5 \\
SLTP & 5 & 16,1 \\
SLTA & 6 & 19,4 \\
Perguruan Tinggi & 1 & 3,2 \\
\hline Total & $\mathbf{3 1}$ & $\mathbf{1 0 0 , 0}$ \\
\hline
\end{tabular}

Sumber : Data primer 
Jumlah responden KK di Kelurahan Wukirsari terbanyak berusia 51-60 tahun yaitu $10 \mathrm{KK}(32,3 \%)$ dan yang paling sedikit berusia $31-40$ tahun $(6,5 \%)$. Responden KK yang memiliki pekerjaan lain-lain diluar yang tercantum di dalam kuesioner lebih besar yaitu $10(32,3 \%)$ dan pekerjaan responden KK yang paling sedikit adalah Guru sebanyak $1(3,2 \%)$. Jumlah responden KK berdasarkan pendidikan terbanyak adalah SD (Sekolah Dasar) yaitu sebesar $8(25,8 \%)$ dan yang paling sedikit adalah pendidikan Perguruan Tinggi sebesar 1 (3,2\%). Jumlah responden $\mathrm{KK}$ berdasarkan pendidikan terbanyak adalah SD (Sekolah Dasar) yaitu sebesar $8(25,8 \%)$ dan yang paling sedikit adalah pendidikan Perguruan Tinggi sebesar $1(3,2 \%)$.

Tabel 4. Pengetahuan tentang Kesiapsiagaan Keluarga Disabilitas dalam Menghadapi Bencana di Kelurahan Wukirsari, Imogiri, Bantul Juni $2020(n=31)$

\begin{tabular}{lccc}
\hline Pengetahuan & Fruekuensi (F) & Presentase (F) & Sig \\
\hline Pre Test & & & \\
Baik & 18 & $58,1 \%$ & \\
Cukup & 11 & $35,5 \%$ & \\
Kurang & 2 & $6,5 \%$ & \\
Post Test & & & \\
Baik & 28 & $90,3 \%$ & \\
Cukup & 3 & $9,6 \%$ & 0,000 \\
\hline Total & 31 & 100,0 & \\
\hline
\end{tabular}

Sumber : Data primer

Tabel 5. Sikap Kesiapsiagaan Keluarga Disabilitas dalam Menghadapi Bencana di Wukirsari, Bantul Juni 2020 (n=31)

\begin{tabular}{lccc}
\hline Pengetahuan & Fruekuensi (F) & Presentase (F) & Sig \\
\hline Pre Test & & & \\
Sangat Setuju & 19 & $61,3 \%$ & \\
Setuju & 11 & $35,5 \%$ & \\
Kurang Setuju & 1 & $3,2 \%$ & \\
Post Test & & & \\
Sangat Setuju & 30 & $96,8 \%$ & 0,000 \\
Setuju & 1 & $3,2 \%$ & \\
\hline Total & 31 & 100,0 &
\end{tabular}

Sumber: Data Primer 
Data di dalam tabel menunjukkan bahwa pengetahuan KK sebelum dilakukan tindakan penyuluhan dan pelatihan (pre test) terdapat 3 macam pengetahuan yaitu baik, cukup, dan kurang. Tingkat pengetahuan terbanyak adalah kategori baik yaitu sebesar 18 $(58,1 \%)$, kategori cukup $11(35,5 \%)$ dan kategori kurang sebesar $2(6,5 \%)$. Namun setelah dilakukan tindakan penyuluhan dan pelatihan mengenai kesiapsiagaan keluarga disabilitas dalam menghadapi bencana pengetahuan menjadi meningkat dan hanya ada 2 (dua) kategori, yaitu kategori baik dan cukup. Kategori baik sebesar $28(90,3 \%)$ dan kategori cukup sebesar $3(9,7 \%)$.

Sedangkan terkait dengan sikap KK sebelum dilakukan tindakan penyuluhan dan pelatihan (pre test) terdapat 3 (tiga) kategori yaitu Sangat setuju, Setuju dan Kurang setuju. Kategori terbanyak adalah kategori Sangat setuju yaitu sebesar 19 $(61,3 \%)$, kategori setuju $11(35,5 \%)$ dan kategori kurang setuju sebesar $1(3,2 \%)$.

Setelah dilakukan tindakan penyuluhan dan pelatihan mengenai kesiapsiagaan keluarga disabilitas dalam menghadapi bencana pengetahuan menjadi meningkat dan hanya ada 2 (dua) kategori, yaitu kategori Sangat setuju dan Setuju. Kategori sangat setuju sebesar 30 $(96,8 \%)$ dan kategori setuju sebesar 1 $(3,2 \%)$.

\section{PEMBAHASAN}

Tabel 4 menunjukkan bahwa terdapat Pengetahuan responden KK sebelum dilakukan tindakan penyuluhan dan pelatihan (pre test) terdapat 3 tingkat pengetahuan yaitu baik, cukup, dan kurang. Kategori terbanyak adalah kategori baik yaitu sebesar $18(58,1 \%)$, kategori cukup $11(35,5 \%)$ dan kategori kurang sebesar $2(6,5 \%)$. Namun setelah dilakukan tindakan penyuluhan dan pelatihan mengenai kesiapsiagaan keluarga disabilitas dalam menghadapi bencana pengetahuan menjadi meningkat dan hanya ada 2 (dua) kategori, yaitu kategori baik dan cukup. Kategori baik sebesar $28(90,3 \%)$ dan kategori cukup sebesar 3 (9,7\%). Pengetahuan adalah hasil dari tahu dan terjadi setelah orang atau kelompok melakukan pengideraan suatu objek dimana pengetahuan akan membentuk tindakan seseorang (Notoatmodjo, 2012).

Pengetahuan yang diperoleh responden sesuai dengan bentuk dan macam pengetahuan menurut Notoatmodjo (2012) adalah pengetahuan yang berdasar empiris atau pengamatan indera yang diperoleh dengan melakukan pengamatan dan observasi diri pribadi secara berulang-ulang.

Berdasarkan hasil penelitian yang dilakukan setelah $\mathrm{KK}$ reponden mendapatkan penyuluhan dan pelatihan terjadi peningkatan pengetahuan $32,2 \%$ dari hasil sebelum dilakukan penyuluhan dan pelatihan $58,1 \%$ dan setelah dilakukan penyuluhan dan pelatihan sebesar $90,3 \%$. Hal tersebut sesuai dengan Notoatmodjo (2012) yang menyebutkan bahwa yang mempengaruhi peningkatan pengetahuan adalah factor pendidikan, infomasi, dan media. Kebencanaan membutuhkan pengetahuan sehingga dimungkinkan untuk mengingat rangkaian kejadian kebencanaan yang disebabkan oleh faktor alam maupun non alam yang dapat menimbukan kerugian di berbagai bidang (Adiwijaya, 2016). Dengan demikian dapat disimpulkan bahwa family disaster planning pada disabilitas dapat meningkatkan pengetahuan menjadi tingkat baik dengan $\mathrm{p}<0.005$. 
Tabel 5 menunjukkan bahwa terdapat Sikap responden sebelum dilakukan tindakan penyuluhan dan pelatihan (pre test) terdapat 3 (tiga) kategori yaitu Sangat setuju, Setuju dan Kurang setuju. Kategori terbanyak adalah kategori Sangat setuju yaitu sebesar 19 $(61,3,1 \%)$, kategori setuju $11(35,5 \%)$ dan kategori kurang setuju sebesar $1(3,2 \%)$.

Setelah dilakukan tindakan penyuluhan dan pelatihan mengenai kesiapsiagaan keluarga disabilitas dalam menghadapi bencana pengetahuan menjadi meningkat dan hanya ada 2 (dua) kategori, yaitu kategori Sangat setuju dan Setuju. Kategori sangat setuju sebesar 30 $(96,8 \%)$ dan kategori setuju sebesar 1 $(3,2 \%)$. Dan berpengaruh signifikan $\mathrm{p}<0.005$ family disaster planning terhadap sikap disabilitas. Sehingga sikap dalam bencana adalah pola perilaku seseorang terhadap suatu kejadian untuk proses antisipatif ketika terjadi suatu peristiwa (Notoatmodjo, 2012). Dilaksanakannya penelitian ini bertujuan untuk dapat meningkatkan dan merubah sikap KK responden menjadi sikap yang positif sehingga mampu dengan sigap dan siap untuk dapat menghadapi bencana dan menolong anggota keluarga yang mengalami disabilitas. Komponen yang menunjang dalam hal ini adalah kognitif, afektif, dan konatif.

Berdasarkan hasil penelitian yang dilakukan setelah KK reponden mendapatkan penyuluhan dan pelatihan terjadi peningkatan sikap 35,5\% dari hasil sebelum dilakukan penyuluhan dan pelatihan $61,3 \%$ dan setelah dilakukan penyuluhan dan pelatihan sebesar $96,8 \%$. Sejalan dengan Notoatmodjo (2012) faktor yang berpengaruh dalam pembentukan dan peningkatan sikap pada responden dalam penelitian ini adalah pengalaman pribadi, kebudayaan, media masa dan Institusi. Kesiapsiagaan menghadapi bencana adalah waktu untuk tanggap darurat individu atau suatu kelompok dalam menghadapi kejadian darurat tersebut sehingga penting penanganan yang cepat dan tepat sebagai tanggap bencana pada tahap awal ketika bantuan dari pihak luar belum datang (Erlia, Kumalawati dan Aristin, 2017).

Dapat disimpulkan bahwa sikap kesiapsiagaan keluarga dalam menghadapi bencana dalam tingkatan baik sehingga dapat meminimalkan dampak dari bencana dan lebih tanggap ketika terjadinya bencana terutama pada disabilitas.

\section{KESIMPULAN DAN SARAN}

Keluarga dengan kesiapsiagaan (Family disaster Planning) penting dimiliki terutama di dalam anggota keluarga yang mempunyai anggota disabilitas. Untuk mengurangi risiko bencana diperlukan pengetahuan sedangkan sikap dibutuhkan dalam bertindak ketika terjadi bencana. Sehingga masyarakat mempunyai peran yang penting dalam terjadinya bencana (Matsuda dan Okada, 2006). Adapun Penelitian ini membutikan adanya family disaster planning dalam masyarakat dapat meningkatkan pengetahuan dan sikap $\mathrm{p}<0.005$ baik sebelum dan setelah dilakukan tindakan penyuluhan dan pelatihan mengenai kesiapsiagaan keluarga disabilitas dalam menghadapi bencana. Pengetahuan keluarga setelah mendapatkan penyuluhan dan pelatihan mengenai kesiapsiagaan keluarga disabilitas dalam menghadapi bencana meningkat menjadi $32,2 \%$ hasil pre test $58,1 \%$ dan hasil post test $90,3 \%$. Sedangkan sikap keluarga meningkat 
menjadi $35,5 \%$ hasil pre test $61,3 \%$ dan post test menjadi $96,8 \%$ ).

Saran untuk keluarga meliputi : 1)

Keluarga terutama yang memiliki anggota keluarga dengan disabilitas perlu konsisten dalam menerapkan penanganan dan kesiapsiagaan dalam menghadapi bencana berdasarkan informasi yang telah diperoleh; 2) Keluarga perlu bekerjsama dengan anggota keluarga lainnya untuk mempersiapkan segala kebutuhan yang diperlukan jika suatu saat terjadi bencana; 3) Kepala keluarga dan anggota keluarga yang lainnya sering bertemu, komunikasi dan berkoordinasi untuk saling mengingatkan tentang hal penting saat terjadi bencana; 4) Kepala keluarga membagi tugas dan peran dengan anggota keluarga yang lain mengenai siapa yang akan bertanggungjawab dalam melindungi dan menolong anggota keluarga yang mengalami disabilitas agar selamat dari bencana; 5) Adanya koordinasi dan kerjasama diantara anggota keluarga terkait dengan penempatan, pengaturan dan peletakkan benda atau barang-barang di dalam rumah agar tidak berisiko menciderai anggota keluarga saat terjadi bencana; 6) Keluarga dapat mengatasi keadaan darurat dengan mempersiapkan sebelumnya dan bekerja sama dengan anggota keluarga lainnya karena keluarga merupakan tombak utama bagi para disabilitas. Kesiapsiagaan merupakan kunci untuk bertahan pada saat darurat dan mengelola kekacauan yang terjadi sesudahnya. Banyak hal yang harus dipersiapkan untuk persiapan keluarga menghadapi bencana alam. Salah satu cara untuk mempersiapkannya adalah dengan menyiapkan peralatan siaga bencana serta kebutuhan lainnya (CINCH, 2011).

Saran untuk Instansi terkait meliputi : 1) Tagana, BPBD maupun Dinas Sosial
Kabupaten perlu adanya pendampingan kesiapsiagaan bencana di masyarakat terutama di masing-masing keluarga setelah diberikan penyuluhan maupun pelatihan. Pendampingan yang dapat dilakukan misalnya dengan membuat perencanaan dan perancangan untuk dapat meningkatkan kesiapan atau kesiapsiagaan masyarakat atau masingmasing keluarga dengan pelaksanaan dan evaluasi secara rutin

Saran untuk peneliti selanjutnya yaitu menggunakan data penelitian ini meningkatkan kesiapsiagaan di masyarakat dengan penilaian Desa Siaga Bencana. Peneliti selanjutnya diharapkan dapat menyusun program-program terkait dengan indikator keluarga siaga bencana yang masih kurang atau rendah dalam pelaksanaannya.

\section{DAFTAR RUJUKAN}

Adiwijaya, C. (2016). Pengaruh Pengetahuan Kebencanaan dan sikap Masyarakat terhadap Kesiapsiagaan Menghadapi Bencana Tanah Longsor', pp. 81-101.

Azizah, Y. N., Ratnawati, R. dan Setyoadi. (2015). Pengalaman Perawat dalam Melakukan Penilaian Cepat Kesehatan Kejadian Bencana pada Tanggap Darurat Bencana Erupsi Gunung Kelud Tahun 2014 di Kabupaten Malang (Studi Fenomologi)', Jurnal Ilmu Keperawatan, 3(2), pp. 129-143. Available at: http://jik.ub.ac.id/index.php/jik/artic le/view/41/60.

Bakornas Penanggulangan bencana. (2007). Pengenalan Karakteristik 
Bencana dan Upaya Mitigasinya di Indonesia. Edisi II. Jakarta.

Bapennas. (2014). Buku Pegangan Perencanaan Pembangunan Daerah 2015 Membangun Ketangguhan Bangsa Melalui Upaya Pengurangan Resiko Bencana. Available at: http://www.bnpb.go.id/publikasi/bu $\mathrm{ku}$ diakses pada 10 Oktober 2020 jam 21.00.

BNPB. (2018). Data Informasi Bencana Indonesia. Available at: http://bnpb.cloud/dibi/laporan4.

CINCH. (2011). Emergency preparedness for families of children with needs', pp. 1-15.

Dwisiwi, R. S. et al. (2012). Pengembangan Teknik Mitigasi Dan Manajemen Bencana Alam Gempabumi Bagi Komunitas SMP Di Kabupaten Bantul Yogyakarta', in Prosiding Seminar Nasional Penelitian Pendidikan dan Penerapan MIPA. Yogyakarta: Fakultas MIPA Universitas Negeri Yogyakarta.

Erlia, D., Kumalawati, R. dan Aristin, N. F. (2017). Analisis Kesiapsiagaan Masyarakat dan Pemerintah Menghadapi Bencana Banjir di Kecamatan Martapura Barat Kabupaten Banjar', JPG (Jurnal Pendidikan Geografi), pp. 15-24.

Firmansyah, I., Rasni, H. dan Rondhianto. (2014). Hubungan Pengetahuan dengan Perilaku Kesiapsiagaan dalam Menghadapi Bencana Banjir dan Longsor pada Remaja Usia 15-
18 tahun di SMA Al-Hasan Kemiri Kecamatan Panti Kabupaten Jember', Universitas Jember, 1, pp. 1-8. Available at: http://repository.unej.ac.id/bitstream /handle/123456789?60652/Iman.

Ikbal, R. . dan Sari, R. . (2018). Kesiapsiagaan Menghadapi Bencana Gempa Bumi', pp. 40-46.

Matsuda, Y. dan Okada, N. (2006). Community diagnosis for suitanable disaster preparedness', Journal of Natural Disaster Science, 28(1), pp. 25-33.

Notoatmodjo, S. (2012). Promosi Kesehatan dan Prilaku Kesehatan'. Jakarta: Rineka Cipta, pp. 131-207.

Nurudin, A. (2015). Pengaruh Pelatihan Penanggulangan Bencana Gempa Bumi Terhadap Kesiapsiagaan Siswa Kelas VII di SMP Negeri 1 Imogiri Bantul Yogyakarta. UNISA.

UNISDR. (2014). Living with disability and disasters: UNISDR 2013 Survey on Living With Disabilities and Disasters-Key Findings. Available at:

http://www.unisdr.org/2014/iddr/do cuments/2013DisabilitySurveryRep ort_030714.pdf.

Wardhana, H. (2015). Merajut Masa Depan Indonesia dengan "Kembali Kepada Keluarga". Available at: http://www.kompasiana.com/publis hed .

Wolf-Fordham, S. et al. (2015). Emergency preparedness of families 
of children with developmental disabilities; What public health and safety emergency planners need to know', JEmerg Manag, 13(1), pp. $7-18$. doi: https://doi.org/10.5055/jem.2015.02 13.Emergency. 